\title{
Complete Genome Sequence Resources for the Onion Pathogen, Pantoea ananatis OC5a
}

\author{
Jo Ann E. Asselin, ${ }^{1}$ Jean M. Bonasera, ${ }^{2}$ Tyler C. Helmann, ${ }^{1}$ Steven V. Beer, ${ }^{2}$ and \\ Paul V. Stodghill, ${ }^{1,+}$ \\ ${ }^{1}$ Emerging Pests and Pathogens Research Unit, Robert W. Holley Center for Agriculture and Health, \\ Agricultural Research Service, United States Department of Agriculture, Ithaca, NY \\ ${ }^{2}$ School of Integrative Plant Science, Plant Pathology and Plant-Microbe Biology Section, Cornell \\ University, Ithaca, NY
}

\begin{abstract}
Here, we report on the genomic sequence and annotation for Pantoea ananatis OC5a, a strain that was isolated from an onion bulb grown in New York and that is pathogenic to onion, causing center rot of onion. OC5a is the first $P$. ananatis strain pathogenic to onion from New York to be completely assembled and sequenced. Having been assembled using long PacBio reads and high-fidelity Illumina reads, this genome is closed, complete, and of high quality.
\end{abstract}

\section{Genomic Resource Announcement}

Center rot (Agarwal et al. 2019) is a important disease of onion (Allium cepa) and other alliums that can result in significant crop loss. Symptoms include water soaking of leaves and rot of individual bulb scales. To date, strains from four species of the genus Pantoea have been shown to cause this disease: Pantoea agglomerans (Hattingh and Walters 1981), P. ananatis (Gitaitis and Gay 1997), P. allii (Brady et al. 2011), and P. stewartii subsp. indologenes (Stumpf et al. 2018). Bacteria of the genus Pantoea are rod-shaped, Gram-negative members of the family Erwiniaceae (Adeolu et al. 2016). They are noted for their production of yellow pigment, a carotenoid that provides resistance to ultraviolet radiation and reactive oxygen species (Walterson and Stavrindes 2015). In New York, $P$. ananatis strains are the most frequently isolated center rot pathogens from onion. $P$. ananatis strains have been shown to be vectored by thrips (Dutta et al. 2014; Gitaitis et al. 2003), and several gene clusters have been shown to be critical for pathogenicity (Asselin et al. 2018; Shyntum et al. 2015; Stice et al. 2018) or survival (Stice et al. 2020) within onion.

At writing, there are $59 \mathrm{P}$. ananatis genomes deposited in NCBl's RefSeq repository (O'Leary et al. 2015), of which 9 are marked "complete." Complete genomes exist for two other onion-pathogenic strains of $P$. ananatis, LMG 20103 (De Maayer et al. 2010) and 97-1R (Stice et al. 2018).

$P$. ananatis OC5a was isolated from an onion bulb grown in Orange County, NY in 2009. Previously (Asselin et al. 2018), OC5a was shown to be virulent on onion and to possess the HiVir gene cluster, which is essential for pathogenesis. In light of these results, we chose to sequence OC5a in order to in order to facilitate future studies of HiVir and its role in center rot of onion.

Bacteria were cultured overnight in $5 \mathrm{ml}$ of Luria-Bertani broth at $28^{\circ} \mathrm{C}$ with shaking at $200 \mathrm{rpm}$. Cell pellets were generated from $1 \mathrm{ml}$ of overnight culture and pelleted by centrifugation at $3,400 \times g$ for $5 \mathrm{~min}$. Pellets were rinsed with $1 \mathrm{ml}$ of water and pelleted as before.

\footnotetext{
${ }^{\dagger}$ Corresponding author: P. V. Stodghill; paul.stodghill@usda.gov

*The $e$-Xtra logo stands for "electronic extra" and indicates that supplementary materials are published
} online.

The author(s) declare no conflict of interest.

Accepted for publication 13 March 2021.

This article is in the public domain and not copyrightable. It may be freely reprinted with customary crediting of the source. The American Phytopathological Society, 2021.

\section{Keywords}

bacterial pathogens, genomics, microbegenome sequencing 
Table 1. Summary of PacBio sequences, Illumina sequences, genome assemblies, and genome annotations

\begin{tabular}{lr} 
Parameters $^{\text {a }}$ & Pantoea ananatis OC5a \\
PacBio sequences & 177,195 \\
Number of reads & $1,464,867,561$ \\
Number of bases & $294 \times$ \\
Coverage & 35 \\
Minimum length & 47,657 \\
Maximum length & 7728 \\
Median length & 8267 \\
Mean length & 11,103 \\
$N_{50}$ & 49,133 \\
L $_{50}$ & \\
Illumina sequences & 914,529 \\
Number of reads & $459,093,558$ \\
Number of bases & $92 \times$ \\
Coverage & \\
Assembled genome & SAMN15405802 \\
GenBank BioSample & $4(1+3)$ \\
Replicons (chromosome + plasmids) & $3,980,968$ \\
Genome size (bp) & 53.6 \\
G+C content (chromosome, \%) & 4,582 \\
Predicted genes & 4,392 \\
Protein-coding genes & 22 \\
RNA genes & 70 \\
Pseudo genes & 4,39 \\
\hline
\end{tabular}

${ }^{a}$ PacBio and Illumina coverage reported are relative to the raw reads and the final genome size. Number of Illumina reads reported is number of read pairs.

DNA was isolated according to a modified protocol provided by Xing Ma (Cornell University) (Liu et al. 2020), which was itself modified from Booher et al. (2015). A detailed description of the method is provided in Supplementary File S1. To summarize, the bacteria were lysed and DNA was extracted from the samples. This DNA was washed several times and RNA was removed using RNase A (Sigma-Aldrich). The final DNA was quantified using the PicoGreen dsDNA Quantitation Reagent (Molecular Probes) and a VersaFluor Fluorometer (Bio-Rad) and via NanoDrop Spectrophotometer (Thermo Fisher Scientific).

The protocol for the PacBio library preparation is described elsewhere (Mathers et al. 2015). Briefly, the DNA was sheared to 10 to $15 \mathrm{~kb}$ using Covaris $\mathrm{g}$-Tubes (Covaris) with $\geq 7-\mathrm{kb}$ size selection on BluePippin using $0.75 \%$ cassettes. The library was sequenced on a PacBio PSII (Pacific Bioscience) at the Icahn School of Medicine, Mount Sinai, NY. P6/C4 chemistry and a movie collection length of $6 \mathrm{~h}$ were used. Summary statistics of the PacBio sequences are shown in Table 1.

For Illumina sequencing, the DNA library was prepared using the NEBNext Ultra II FS DNA library preparation kit for Illumina with NEBNext multiplex oligonucleotides (New England Biolabs). AMPure XP beads (Beckman Coulter) were used for DNA size selection and purification. The DNA library was sequenced on a MiSeq instrument (lllumina) with the 2 (paired-end) $\times 250$-bp mode. Summary statistics of the lllumina sequences are shown in Table 1.

A draft genome sequence was assembled from the PacBio reads using Flye v2.6 (Kolmogorov et al. 2019) with the following extra parameters: "-genome-size 5.1m", "-plasmids", and "-iterations 2". The assembly graph produced by Flye showed that all of the unitigs in the assembly represented closed circular replicons (i.e., a single chromosome and several plasmids). The Illumina reads were trimmed and filtered using Trimmomatic (Bolger et al. 2014) v0.39 with the following parameters: ILLUMINACLIP:inputs/NEBnext_PE.fa:2:30:10 LEADING:3 TRAILING:3 SLIDINGWINDOW:4:20 MINLEN:50. The trimmed and paired reads were used to polish the draft genome using NextPolish v1.1.0 (Hu et al. 2019) with the "task" parameter set to 1212. Custom Perl (https://www.perl.org/) scripts were used to rotate and reindex the polished assembly so that, for instance, DnaA appeared as the first gene on the positive strand close to index 1.

Because size selection was performed prior to PacBio sequencing, we investigated the possibility that OC5a might have small plasmids that were not sequenced. Putative plasmid DNA was isolated using the Monarch Plasmid Miniprep Kit (New England BioLabs). The isolated DNA demonstrated a clear band that was $<10 \mathrm{~kb}$. The restriction enzyme, Taql (New England 
BioLabs), was applied to the DNA isolated from the band and the resulting fragments were ligated into the high-copy-number vector, pBC SK- (Stratagene), cut with Clal. One of the cloned fragments was sequenced and used as a starting point for primer walking. Iteratively, primers were designed that could amplify successive sections of the plasmid for sequencing, then primer design, and so on. Portions of the plasmid were amplified using OneTaq (New England BioLabs), and each fragment of DNA was amplified and sequenced by Sanger sequencing at the Cornell Institute of Biotechnology Core Facilities at least twice. Sequencing reactions were assembled using SeqMan Pro 15 (DNAStar) into the 5,228-bp sequence of a closed plasmid, which we have called plasmid $\mathrm{C}$, or $\mathrm{pOC5aC}$. The sequence for $\mathrm{pOC5aC}$ was added to the other OC5a replicons for further processing.

Summary statistics of the Flye+NextPolish genome assembly are shown in Table 1.

The final genomic sequences were annotated using NCBI's PGAP (Tatusova et al. 2016) pipeline as part of the GenBank (Clark et al. 2015) submission process. Summary statistics of the genome annotation are shown in Table 1.

Computational comparisons between OC5a and other Pantoea and $P$. ananatis genomes can be found in Supplementary File S2. Among other results, we show that $P$. ananatis PNA 971R (Stice et al. 2018) is the most similar of the complete RefSeq genomes to OC5a. Depending upon the method used, the sequence of OC5a has an average identify of between 99.22 and 99.30\% with PNA 97-1R. The RefSeq-annotated proteomes of OC5a and PNA 97-1R contain 4,392 and 4,465 proteins, respectively, with 3,403 and 3,921 of OC5a's proteins aligning (blastp) (Camacho et al. 2009) with PNA 97-1R's using e-value cutoffs of 1e-100 and 1e-50, respectively.

Data availability. The genome sequence and annotations for OC5a are available from NCBl's GenBank database (Clark et al. 2015) under the accession numbers CP059083 to CP059086. The raw PacBio and Illumina sequence files are available from NCBl's Sequence Read Archive (Leinonen et al. 2011) under the accession numbers SRR12158098 and SRR12158099, respectively.

\section{Acknowledgments}

We thank X. Ma (Cornell University) for providing us with the DNA isolation protocol and R. Sebra at Mount Sinai for preparing and performing the PacBio sequencing. The Illumina and Sanger sequencing were performed by Cornell Institute of Biotechnology Core Facilities. Mention of trade names or commercial products in this publication is solely for the purpose of providing specific information and does not imply recommendation or endorsement by the U.S. Department of Agriculture. USDA is an equal opportunity provider and employer.

\section{Literature Cited}

Adeolu, M., Alnajar, S., Naushad, S., and Gupta, R. S. 2016. Genome-based phylogeny and taxonomy of the "Enterobacteriales": Proposal for Enterobacterales ord. nov. divided into the families Enterobacteriaceae, Erwiniaceae fam. nov., Pectobacteriaceae fam. nov., Yersiniaceae fam. nov., Hafniaceae fam. nov., Morganellaceae fam. nov., and Budviciaceae fam. nov. Int. J. Syst. Evol. Microbiol. 66:5575-5599.

Agarwal, G., Stumpf, S., Kvitko, B., and Dutta, B. 2019. Center rot of onion. Plant Health Instruct. https://www.apsnet.org/edcenter/disimpactmngmnt/topc/Pages/ CenterRotOnion.aspx

Asselin, J. E., Bonasera, J. M., and Beer, S. V. 2018. Center rot of onion (Allium cepa) caused by Pantoea ananatis requires pepM, a predicted phosphonaterelated gene. Mol. Plant-Microbe Interact. 31:1291-1300.

Bolger, A. M., Lohse, M., and Usadel, B. 2014. Trimmomatic: A flexible trimmer for Illumina sequence data. Bioinformatics 30:2114-2120.

Booher, N. J., Carpenter, S. C. D., Sebra, R. P., Wang, L., Salzberg, S. L., Leach, J. E., and Bogdanove, A. J., 2015. Single molecule real-time sequencing of Xanthomonas oryzae genomes reveals a dynamic structure and complex TAL (transcription activator-like) effector gene relationships. Microb. Genomics 1.

Brady, C. L., Goszczynska, T., Venter, S. N., Cleenwerck, I., De Vos, P., Gitaitis, R. D., and Coutinho, T. A. 2011. Pantoea allii sp. nov., Isolated from onion plants and seed. Int. J. Syst. Evol. Microbiol. 61:932-937.

Camacho, C., Coulouris, G., Avagyan, V., Ma, N., Papadopoulos, J., Bealer, K., and Madden, T. L. 2009. BLAST+: Architecture and applications. BMC Bioinf. 10:421.

Clark, K., Karsch-Mizrachi, I., Lipman, D. J., Ostell, J., and Sayers, E. W. 2015. GenBank. Nucleic Acids Res. 44:D67-D72.
De Maayer, P., Chan, W. Y., Venter, S. N., Toth, I. K., Birch, P. R. J., Joubert, F., and Coutinho, T. A. 2010. Genome sequence of Pantoea ananatis LMG20103, the causative agent of Eucalyptus blight and dieback. J. Bacteriol. 192:29362937.

Dutta, B., Barman, A. K., Srinivasan, R., Avci, U., Ullman, D. E., Langston, D. B., and Gitaitis, R. D. 2014. Transmission of Pantoea ananatis and P. agglomerans, causal agents of center rot of onion (Allium cepa), by onion thrips (Thrips tabaci) through feces. Phytopathology 104:812-819.

Gitaitis, R. D., and Gay, J. D. 1997. First report of a leaf blight, seed stalk rot, and bulb decay of onion by Pantoea ananas in Georgia. Plant Dis. 81:1096.

Gitaitis, R. D., Walcott, R. R., Wells, M. L., Perez, J. C. D., and Sanders, F. H. 2003. Transmission of Pantoea ananatis, causal agent of center rot of onion, by tobacco thrips, Frankliniella fusca. Plant Dis. 87:675-678.

Hattingh, M. J., and Walters, D. F. 1981. Stalk and leaf necrosis of onion caused by Erwinia herbicola. Plant Dis. 65:615-618.

Hu, J., Fan, J., Sun, Z., and Liu, S. 2019. NextPolish: A fast and efficient genome polishing tool for long-read assembly. Bioinformatics 36:2253-2255.

Kolmogorov, M., Yuan, J., Lin, Y., and Pevzner, P. A. 2019. Assembly of long, errorprone reads using repeat graphs. Nat. Biotechnol. 37:540-546.

Leinonen, R., Sugawara, H., and Shumway, M. 2011. The Sequence Read Archive. Nucleic Acids Res. 39:D19-D21.

Liu, Y., Ma, X., Helmann, T. C., McLane, H., Stodghill, P., Swingle, B., Filiatrault, M. J., and Perry, K. L. 2020. Complete genome sequence of a gram-positive bacterium, Leifsonia sp. strain PS1209, a potato endophyte. Microbiol. Resour. Announce. 9:e00447-20. 
Mathers, A. J., Stoesser, N., Sheppard, A. E., Pankhurst, L., Giess, A., Yeh, A. J., Didelot, X., Turner, S. D., Sebra, R., Kasarskis, A., Peto, T., Crook, D., and Sifri, C. D. 2015. Klebsiella pneumoniae carbapenemase (KPC)-producing $K$. pneumoniae at a single institution: Insights into endemicity from whole-genome sequencing. Antimicrob. Agents Chemother. 59:1656-1663.

O'Leary, N. A., Wright, M. W., Brister, J. R., Ciufo, S., Haddad, D., McVeigh, R., Rajput, B., Robbertse, B., Smith-White, B., Ako-Adjei, D., Astashyn, A., Badretdin, A., Bao, Y., Blinkova, O., Brover, V., Chetvernin, V., Choi, J., Cox, E., Ermolaeva, O., Farrell, C. M., Goldfarb, T., Gupta, T., Haft, D., Hatcher, E., Hlavina, W., Joardar, V. S., Kodali, V. K., Li, W., Maglott, D., Masterson, P., McGarvey, K. M., Murphy, M. R., O'Neill, K., Pujar, S., Rangwala, S. H., Rausch, D., Riddick, L. D., Schoch, C., Shkeda, A., Storz, S. S., Sun, H., Thibaud-Nissen, F., Tolstoy, I., Tully, R. E., Vatsan, A. R., Wallin, C., Webb, D., Wu, W., Landrum, M. J., Kimchi, A., Tatusova, T., DiCuccio, M., Kitts, P., Murphy, T. D., and Pruitt, K. D. 2015. Reference sequence (RefSeq) database at NCBI: Current status, taxonomic expansion, and functional annotation. Nucleic Acids Res. 44:D733-D745.
Shyntum, D. Y., Theron, J., Venter, S. N., Moleleki, L. N., Toth, I. K., and Coutinho, T. A. 2015. Pantoea ananatis utilizes a type VI secretion system for pathogenesis and bacterial competition. Mol. Plant-Microbe Interact. 28:420-431.

Stice, S. P., Stumpf, S. D., Gitaitis, R. D., Kvitko, B. H., and Dutta, B. 2018. Pantoea ananatis genetic diversity analysis reveals limited genomic diversity as well as accessory genes correlated with onion pathogenicity. Front. Microbiol. 9:184.

Stice, S. P., Thao, K. K., Khang, C. H., Baltrus, D. A., Dutta, B., and Kvitko, B. H. 2020. Thiosulfinate tolerance is a virulence strategy of an atypical bacterial pathogen of onion. Curr. Biol. 30:3130-3140.e6.

Stumpf, S., Kvitko, B., Gitaitis, R., and Dutta, B. 2018. Isolation and characterization of novel Pantoea stewartii subsp. indologenes strains exhibiting center rot in onion. Plant Dis. 102:727-733.

Tatusova, T., DiCuccio, M., Badretdin, A., Chetvernin, V., Nawrocki, E. P., Zaslavsky, L., Lomsadze, A., Pruitt, K. D., Borodovsky, M., and Ostell, J. 2016. NCBI Prokaryotic Genome Annotation Pipeline. Nucleic Acids Res. 44:6614-6624.

Walterson, A. M., and Stavrinides, J. 2015. Pantoea: Insights into a highly versatile and diverse genus within the Enterobacteriaceae. FEMS Microbiol. Rev. 39:968984. 